\title{
Hyperoside Protects Against Pressure Overload-Induced Cardiac Remodeling via the AKT Signaling Pathway
}

\author{
Xiaofang Wang Yuan Liu Lili Xiao Ling Li Xiaoyan Zhao Lulu Yang \\ Ning Chen Lu Gao Jinying Zhang \\ Department of Cardiology, the First Affiliated Hospital of Zhengzhou University, Zhengzhou, China
}

\section{Key Words}

Hyperoside $\cdot$ Cardiac hypertrophy $\cdot$ AKT $・$ Signaling pathway

\begin{abstract}
Background/Aims: Cardiac hypertrophy is a major predisposing factor for heart failure and sudden cardiac death. Hyperoside (Hyp), a flavonoid isolated from Rhododendron ponticum L., is a primary component of Chinese traditional patent medicines. Numerous studies have shown that Hyp exerts marked anti-viral, anti-inflammatory, anti-oxidant, anti-cancer, anti-ischemic, and particularly cardio-protective effects. However, the effects of Hyp on cardiac hypertrophy have not been explored. The aims of this study were to determine whether Hyp could protect against cardiac remodeling and to clarify the potential molecular mechanisms. Methods: Neonatal rat cardiac myocytes were isolated and treated with different concentrations of Hyp, then cultured with angiotensin II for $48 \mathrm{~h}$. Mice were subjected to either aortic banding or sham surgery (control group). One week after surgery, the mice were treated with Hyp (20 $\mathrm{mg} / \mathrm{kg} /$ day) or vehicle by oral gavage for 7 weeks. Hypertrophy was evaluated by assessing morphological changes, echocardiographic parameters, histology, and biomarkers. Results: Hyp pretreatment suppressed angiotensin II-induced hypertrophy in cardiomyocytes. Hyp exerted no basal effects but attenuated cardiac hypertrophy and dysfunction, fibrosis, inflammation, and oxidative stress induced by pressure overload. Both in vivo and in vitro experiments demonstrated that the effect of Hyp on cardiac hypertrophy was mediated by blocking activation of the AKT signaling pathway. Conclusion: Hyp improves cardiac function and prevents the development of cardiac hypertrophy via AKT signaling. Our results suggest a protective effect of Hyp on pressure overload-induced cardiac remodeling. Taken together, Hyp may have a role in the pharmacological therapy of cardiac hypertrophy.
\end{abstract}




\section{Introduction}

Pathological cardiac hypertrophy is a major predisposing factor for heart failure and sudden cardiac death [1]. Generally, during hypertrophy, myocytes grow in size and contribute to protein synthesis [2]. Although this response may be initially beneficial, sustained cardiac hypertrophy ultimately leads to ventricular dilation and congestive heart failure [3]. Recently, many studies have illustrated that signaling pathways, such as mitogenactivated protein kinases (MAPKs), calcineurin-nuclear factor of activated T cells (NFAT), and phosphatidylinositol 3-kinase (PI3K)/AKT, play important roles in hypertrophic responses [4]. Therefore, pharmacological interventions targeting these signaling pathways may provide promising approaches for preventing cardiac hypertrophy. Unfortunately, despite the clinical use of angiotensin-converting enzyme inhibitors, angiotensin receptor blockers, and $\beta$-blockers, the death rate due to heart failure is increasing every year [2]. Thus, a better understanding of the intracellular signaling pathways that mediate cardiac hypertrophy and identification of novel drugs that disrupt the intracellular signaling pathways are greatly needed.

Hyperoside (Hyp; also known as quercetin 3-0- $\beta$-d-galactoside), a flavonoid isolated from Rhododendron ponticum $L_{\text {. }}$, is a primary component of Chinese traditional patent medicines. Recent studies have shown that Hyp possesses comprehensive pharmacological functions, including anti-inflammatory [5], anti-cancer [6], and anti-fibrosis effects [7]. Furthermore, increasing evidence suggests that Hyp protects against hypoxia/reoxygenationinduced injury in cardiomyocytes by suppressing Bnip3 expression [8]. Hou et al. reported that Hyp significantly improved cardiac function induced by ischemia/reperfusion injury by activating the Nrf2 signaling pathway [9]. It was also demonstrated that Hyp could induce apoptosis and inhibit growth via nuclear factor (NF)- $\kappa B$ signaling both in vitro and in vivo [10]. However, whether Hyp has a beneficial role in cardiac hypertrophy and, if so, the underlying mechanisms remain unclear. Therefore, we aimed to determine whether Hyp could attenuate cardiac hypertrophy and to identify the molecular mechanisms that may be responsible for any protective effects. It is known that pressure overload can activate the renin-angiotensin system and induce the release of angiotensin II (Ang II), which activates the $\mathrm{G} \alpha$ (q) protein-coupled receptor signaling pathway [11]. Thus, Ang II was used in vitro to induce remodeling in cardiomyocytes.

In this study, we investigated whether Hyp could ameliorate cardiac hypertrophy induced by pressure overload in mice. Our results showed that Hyp mitigated cardiac hypertrophy and fibrosis induced by pressure overload and preserved cardiac function. Our in vitro study revealed that pretreatment of Hyp could suppress Ang II-induced cardiomyocyte hypertrophy and oxidative stress. Mechanistically, we revealed that Hyp treatment prevented maladaptive remodeling, which was partially dependent on regulation of the AKT signaling pathway. Based on our results, we believe that Hyp would provide a potential therapeutic strategy for the treatment of cardiac hypertrophy and heart failure.

\section{Materials and Methods}

\section{Reagents}

Hyp (purity $\geq 98 \%$ ) was purchased from Shanghai Winherb Medical S\&T Development (Shanghai, China). All antibodies utilized in this study were obtained from Cell Signaling Technology (Danvers, MA). MK-2206 (hydrochloride) was purchased from Cayman Chemical Company (Ann Arbor, MI). Dulbecco's modified Eagle's medium (DMEM)/F12, fetal bovine serum (FBS), bromodeoxyuridine, penicillin, and streptomycin were purchased from Gibco BRL (Grand Island, NY). All other cell culture reagents were purchased from Sigma-Aldrich (St. Louis, MO). 


\section{Cellular Physiology Cell Physiol Biochem 2018;51:827-841

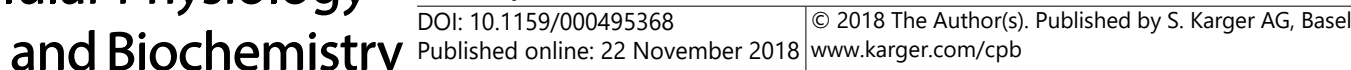 \\ Wang et al.: Hyperoside Modulates Cardiac Hypertrophy}

Animals and animal models

All animal procedures were performed in accordance with the Guide for the Care and Use of Laboratory Animals, published by the US National Institutes of Health (NIH Publication No. 85-23, revised 1996), and were approved by the Animal Care and Use Committee of the First Affiliated Hospital of Zhengzhou University. Male C57/BL6 mice (23.5-27.5 g, 8-10 weeks old) were purchased from the Institute of Laboratory Animal Science, Chinese Academy of Medical Sciences (Beijing, China). A period of 1 week was given for acclimation to the laboratory environment for all animals.

All mice were randomly assigned to aortic banding $(\mathrm{AB})$ or sham groups. $\mathrm{AB}$ was conducted as described previously $[12,13]$. Hyp $(20 \mathrm{mg} / \mathrm{kg} /$ day by oral gavage, suspended in $0.5 \%$ carboxymethyl cellulose solution) or vehicle was given orally for 7 weeks, starting 1 week after AB. Adequate constriction of the aorta was determined by Doppler analysis. A similar procedure, without constricting the aorta, was performed in the sham-operated group. The wall thickness and internal diameter of the left ventricle (LV) were assessed using echocardiography at the indicated time after surgery. At the end of these procedures, the heart, lung, and tibia from the sacrificed mice were harvested, weighed, and analyzed to compare the heart weight/body weight (HW/BW; mg/g), lung weight/body weight (LW/BW; mg/g), and heart weight/ tibia length (HW/TL; $\mathrm{mg} / \mathrm{mm}$ ) ratios between the Hyp-treated and vehicle-treated mice.

\section{Echocardiography and hemodynamic evaluations}

Echocardiography was performed on anesthetized (1.5\% isoflurane) mice using a MyLab 30CV ultrasound system (Biosound Esaote, Inc., Indianapolis, IN) with a 10-MHz linear array ultrasound transducer. The LV was assessed at a frame rate of $120 \mathrm{~Hz}$ in both parasternal long- and short-axis views. The end-systolic and end-diastolic phases are defined as the stage of obtaining the minimum and maximum areas of the LV, respectively. LV end-systolic diameter (LVESD) and LV end-diastolic diameter (LVEDD) were measured at a mid-papillary muscle level at a sweep speed of $50 \mathrm{~mm} / \mathrm{s}$ by LV M-mode tracing.

Cardiac catheterization was used to measure hemodynamic parameters in anesthetized $(1.5 \%$ isoflurane) mice. A microtip catheter sensor (SPR-839; Millar Instruments, Houston, TX) was inserted into the right carotid artery and into the LV. After stabilizing for $15 \mathrm{~min}$, the pressure signal and heart rate were continuously recorded with a Millar Pressure-Volume System (MPVS-400; Millar Instruments) with a Powerlab/4SP A/D converter and then stored and displayed on a personal computer. Data were processed using PVAN data analysis software.

\section{Histological analysis and immunohistochemistry}

Hearts were excised, immediately placed in $10 \%$ potassium chloride solution to ensure that they arrested during diastole, washed with saline solution, fixed with $10 \%$ formalin, and embedded in paraffin. Hearts were cut transversely to the apical side to visualize the LV and right ventricle. Heart sections (4 to 5 mm thick) were stained with hematoxylin and eosin (HE) for histopathology or picro-sirius red (PSR) for collagen deposition analysis. Cross-sectional areas of the myocytes were visualized with FITC-conjugated wheat germ agglutinin (WGA) (Invitrogen, Carlsbad, CA) staining. Single myocytes were measured using a quantitative digital image analysis system (Image Pro-Plus, version 6.0, Media Cybernetics, Rockville, MD). Between 100 and $200 \mathrm{LV}$ myocytes were measured in each group. The LV collagen volume fraction was calculated from the sections stained for PSR, divided by the total area.

For immunohistochemistry, the heart sections were heated using the pressure cooker method for antigen retrieval, incubated with anti-CD31 (ab28364, Abcam, Cambridge, UK) or 4-hydroxynonenal (ab46545, Abcam) followed by incubation with goat anti-rabbit EnVisionTM+/horseradish peroxidase reagent, and stained using a DAB detection kit. For immunofluorescence, heart sections were incubated with anti-CD68 (ab125212, Abcam) and anti-CD45 antibody (ab10558, Abcam). The microvascular density per field was calculated using a quantitative digital image analysis system (Image Pro-Plus, version 6.0). Between 10 and 20 fields were calculated in each group.

\section{Cell culture and treatment}

Briefly, cardiac cells from neonatal rat hearts were isolated in phosphate-buffered saline (PBS) containing $0.03 \%$ trypsin and $0.04 \%$ collagenase type II. Subsequently, neonatal rat cardiac myocytes (NRCMs) were purified by removing cardiac fibroblasts using a differential attachment technique (after $90 \mathrm{~min}$, the cardiac fibroblasts was attached in the dishes, while the NRCMs were still suspended). NRCMs were then seeded at a density of $1 \times 10^{6}$ cells per well in six-well culture plates. After $48 \mathrm{~h}$, the culture medium was replaced with serum-free DMEM/F12 for $12 \mathrm{~h}$ before stimulation with Ang II $(1 \mu \mathrm{M})$. Cells 


\section{Cellular Physiology Cell Physiol Biochem 2018;51:827-841 \begin{tabular}{l|l|l} 
and Biochemistry Published onlIne: 22 November 2018 & $\begin{array}{l}\text { @ } 2018 \text { The Author(s). Published by S. Karger AG, Basel } \\
\text { www.karger.com/cpb }\end{array}$ \\
\hline
\end{tabular} \\ Wang et al.: Hyperoside Modulates Cardiac Hypertrophy}

were incubated with Ang II for $48 \mathrm{~h}$ after starvation with DMEM medium containing $0.5 \%$ FBS overnight to induce hypertrophy. For cells treated with Hyp at different concentrations $(1,5$, or $10 \mu \mathrm{M})$, AKT inhibitor (MK-2206, $50 \mathrm{mM}$ ) was added into the medium before Ang II administration.

\section{Immunoflurescence staining}

Immunofluorescence staining was performed with anti- $\alpha$-actinin antibody (05-384, Millipore, Burlington, MA) to assess the cell cross-sectional area. After washing three times with PBS, the cells were fixed with RCL2 (RCL2-CS100, ALPHELYS, Plaisir, France) and permeabilized with $0.1 \%$ Triton X-100 (Amresco, Solon, $\mathrm{OH}$ ) in PBS for $40 \mathrm{~min}$, then stained with anti- $\alpha$-actinin overnight at a dilution of 1:100 in $1 \%$ goat serum (GTX27481, GeneTex, Irvine, CA). The cells were then incubated with secondary goat antimouse antibody Irdye 800 CW (926-32210, LI-COR, Inc., Lincoln, NE) for 60 min. After washing with PBS, glass slides were used to mount cells on coverslips with ProLong Gold anti-fade reagent with 4'6-diamidino2-phenylindole (DAPI; Invitrogen). The surface areas of NRCMs were measured using image analysis software (Image Pro-Plus, version 6.0) for 40 cells from each group.

\section{Detection of reactive oxygen species in NRCMs}

Myocytes were cultured in six-well plates and pretreated with Hyp and Ang II for the indicated times. Reactive oxygen species (ROS) were then detected by dichlorofluorescein diacetate assay (DCFH-DA). The cells were incubated with DCFH-DA $(10 \mu \mathrm{M})$ for $60 \mathrm{~min}$ at $37^{\circ} \mathrm{C}$, and immunofluorescence was detected using a fluorescence microplate reader (FL600, BioTek, Winooski, VT) normalized to the vehicle-PBS group to control for unwanted sources of variation (excitation/emission wavelength: 485/525 nm), by light microscopy (BX51TRF, Olympus Corporation, Tokyo, Japan).

\section{Quantitative real-time PCR}

Total RNA was isolated from heart tissues or NRCMs using TRIzol Reagent (Invitrogen), and RNA extracts $(20 \mu \mathrm{g})$ were used to synthesize cDNA using Transcriptor First Strand cDNA Synthesis Kit (Roche, Mannheim, Germany). The mRNA levels of the indicated genes were quantified with real-time PCR using SYBR Green (Roche), and the results were normalized relative to GAPDH gene expression. The primers used for real-time PCR are shown in Table 1.

\section{Western blot analysis}

Heart tissues or NRCMs were lysed in RIPA buffer (9806S, Cell Signaling Technology). Proteins were isolated as previously described $[11,12]$, and the lysates $(50 \mu \mathrm{g})$ were subjected to electrophoresis in $10 \%$ sodium dodecyl sulfate polyacrylamide gel electrophoresis and transferred to polyvinylidene fluoride membranes, followed by incubation with specific antibodies overnight at $4^{\circ} \mathrm{C}$. Then, the membranes were incubated with a secondary antibody and scanned using the Odyssey Imaging System (LICOR, Inc.). Specific protein expression levels were normalized relative to GAPDH protein for total cell lysates. The antibodies used for western blot are shown in Table 2.
Table 1. Primer sequences used for RT-PCR. Sequences are listed 5 ' -3 '. . The PCR used the primers in mice. ${ }^{b}$ The PCR used the primers in rat

\begin{tabular}{|c|c|c|}
\hline mRNA & Forward & Reverse \\
\hline ANPa & ACCTGCTAGACCACCTGGAG & CCTTGGCTGTTATCTTCGGTACCGG \\
\hline BNPa & GAGGTCACTCСТАTCСTCTGG & GCCATTTCCTCCGACTTTTCTC \\
\hline$\beta-\mathrm{MHC}^{\mathrm{a}}$ & CCGAGTCCCAGGTCAACAA & CTTCACGGGCACCCTTGGA \\
\hline Col1agenI ${ }^{a}$ & AGGCTTCAGTGGTTTGGATG & CACCAACAGCACCATCGTTA \\
\hline Col1agenIIIa & AAGGCTGCAAGATGGATGCT & GTGCTTACGTGGGACAGTCA \\
\hline CTGFa & AGGGCCTCTTCTGCGATTTC & CTTTGGAAGGACTCACCGCT \\
\hline IL-1a & CCGTGGACCTTCCAGGATGA & GGGAACGTCACACACCAGCA \\
\hline IL-6a & AGTTGCCTTCTTGGGACTGA & TCCACGATTTCCCAGAGAAC \\
\hline TNF- $\alpha^{\mathrm{a}}$ & САTCTTCTCAAAATTCGAGTGACAA & TGGGAGTAGACAAGGTACAACCC \\
\hline MCP-1a & TGGCTCAGCCAGATGCAGT & CCAGCCTACTCATTGGGATCA \\
\hline GAPDH $^{\mathrm{a}}$ & ACTCCACTCACGGCAAATTC & TCTCCATGGTGGTGAAGACA \\
\hline ANPb & AAAGCAAACTGAGGGCTCTGCTCG & TTCGGTACCGGAAGCTGTTGCA \\
\hline $\mathrm{BNPb}$ & TTCCTTAATCTGTCGCCGCTGG & CAGCAGCTTCTGCATCGTGGAT \\
\hline$\beta-\mathrm{MHC}^{\mathrm{b}}$ & TCTGGACAGCTCCCCATTCT & CAAGGCTAACCTGGAGAAGATG \\
\hline SOD ${ }^{\mathrm{b}}$ & AGCCTCССТGACCTGCCTTA & CGCCTCGTGGTACTTCTCCTC \\
\hline Gpx $x^{b}$ & TTCСАТССССАААТGCAAAG & TCAGATGCCCTAAAACCGGAG \\
\hline NADPH p67b & TTCСАТССССАAАTGCAAAG & TCAGATGCCCTAAAACCGGAG \\
\hline $\mathrm{GAPDH}^{\mathrm{b}}$ & GACATGCCGCCTGGAGAAAC & AGCCCAGGATGCCCTTTAGT \\
\hline
\end{tabular}

Table 2. The antibodies used in western blotting

\begin{tabular}{llcc}
\hline Antibody name & \multicolumn{1}{c}{ Company } & $\begin{array}{c}\text { Num } \\
\text { ber }\end{array}$ & $\begin{array}{c}\text { Diluti } \\
\text { on }\end{array}$ \\
\hline TGF- $\beta 1$ & Cell Signaling Technology & 3709 & $1: 1000$ \\
p-Smad2 & Cell Signaling Technology & 3101 & $1: 1000$ \\
T-Smad2 & Cell Signaling Technology & $3103 \mathrm{~s}$ & $1: 1000$ \\
p-Smad3 & Cell Signaling Technology & 9520 & $1: 1000$ \\
T-Smad3 & Cell Signaling Technology & 9513 & $1: 1000$ \\
SOD & Cell Signaling Technology & 2770 & $1: 1000$ \\
Gpx & Cell Signaling Technology & 3206 & $1: 1000$ \\
P67 phox & Cell Signaling Technology & 3923 & $1: 1000$ \\
p-AKT & Cell Signaling Technology & 4060 & $1: 1000$ \\
T-AKT & Cell Signaling Technology & 4691 & $1: 1000$ \\
p-mTOR & Cell Signaling Technology & 2971 & $1: 1000$ \\
T-mTOR & Cell Signaling Technology & 2983 & $1: 1000$ \\
p-GSK3 $\beta$ & Cell Signaling Technology & 9322 & $1: 1000$ \\
T-GSK3 $\beta$ & Cell Signaling Technology & 9315 & $1: 1000$ \\
p-EIF4e & Cell Signaling Technology & 9741 & $1: 1000$ \\
T-EIF4e & Cell Signaling Technology & 2067 & $1: 1000$ \\
GAPDH & Cell Signaling Technology & 2118 & $1: 2000$ \\
Anti-mouse IgG & Cell Signaling Technology & 7076 & $1: 1000$ \\
Anti-rabbit IgG & Cell Signaling Technology & 7074 & $1: 1000$ \\
\hline
\end{tabular}




\section{Cellular Physiology Cell Physiol Biochem 2018;51:827-841

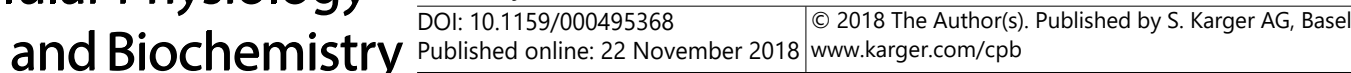 \\ Wang et al.: Hyperoside Modulates Cardiac Hypertrophy}

Statistical analysis

All data were presented as the mean \pm standard deviation. The differences between two groups were determined using unpaired Student's t test. Two-way analysis of variance with the post hoc Turkey test was used to compare the differences among groups. Statistical analysis was performed using SPSS 17.0 (SPSS Inc., Chicago, IL). A value of P less than 0.05 was considered statistically different.

\section{Results}

\section{Hyp inhibits cardiac hypertrophy in vitro}

To determine the role of pretreatment with Hyp in Ang II-induced cardiac hypertrophy, we first evaluated the effect of Hyp on cardiomyocyte hypertrophy in vitro, using primary cultured NRCMs. Cardiac myocytes were pretreated with Hyp at the indicated concentrations for $24 \mathrm{~h}$ and subsequently stimulated with Ang II for $48 \mathrm{~h}$, followed by Hyp with $\alpha$-actinin to measure the cell size. Our results revealed that Hyp pretreatment markedly attenuated the increase in cardiac myocyte size seen in the presence of Ang II after $48 \mathrm{~h}$ of culture in a dose-dependent manner (Fig. 1A-B). In addition, Hyp pretreatment markedly reduced the increased mRNA and protein levels of the hypertrophic markers atrial natriuretic peptide (ANP), B-type natriuretic peptide (BNP), and $\beta$-myosin heavy chain ( $\beta$-MHC) induced by Ang II, especially in the group treated with $10 \mu \mathrm{M}$ Hyp (Fig. 1C-D). Thus, $10 \mu \mathrm{M}$ Hyp was used in subsequent experiments. Then, the cardiomyocytes were co-incubated with Hyp $(10 \mu \mathrm{M})$ and Ang II for different durations $(6,12$, or $24 \mathrm{~h})$. The result demonstrated that Hyp inhibited Ang II-induced reactivation of ANP, BNP, and $\beta$-MHC expression in a time-dependent manner (Fig. 1E). These findings suggested that Hyp protects against cardiac hypertrophy in vitro.

\section{Hyp reduces cardiac hypertrophy and improves cardiac function after chronic pressure} overload in mice

After exploring the effects of Hyp on cardiomyocyte hypertrophy in vitro, we sought to identify whether Hyp could antagonize the hypertrophic response induced by pressure overload. One week after $A B$ surgery, mice were randomly assigned to the Hyp or vehicle treatment groups. Of note, in the sham groups, mice treated with Hyp did not show any pathophysiological alterations in cardiac structure or function compared with vehicle-treated mice. However, compared with the vehicle-treated mice that underwent $A B$, the myocardial hypertrophic response was significantly blocked by Hyp 8 weeks after surgery, as shown by a decrease in heart size and cardiomyocyte cross-sectional area (assessed by HE staining and FITC-conjugated WGA) in the Hyp-AB group (Fig. 2A-B). In parallel, the ratios of HW/ BW, HW/TL, and LW/BW were significantly decreased in Hyp-treated mice compared with vehicle-treated mice 8 weeks after AB (Fig. 2C). Moreover, the mRNA expression levels of the hypertrophic markers ANP, BNP, and $\beta$-MHC were inhibited in the Hyp-treated mice compared to vehicle-treated animals (Fig. 2D). In echocardiography and hemodynamic evaluations, we found that systolic and diastolic functions were improved after treatment with Hyp (with decreased LVEDD and LVESD, and increased fractional shortening and ejection fraction, Table 3). LV pressure-volume loops also showed preserved systolic function in Hyp-treated mice compared with the vehicle-treated mice in the AB groups (with increased $\mathrm{dp} / \mathrm{dt}_{\text {max }^{\prime}}$ and $\mathrm{dp} / \mathrm{dt}_{\min }$, Table 3 ). These results suggest that Hyp could improve cardiac function and suppress cardiac hypertrophy after $\mathrm{AB}$ surgery.

\section{Hyp attenuates cardiac fibrosis and inflammation in vivo}

To further investigate the mechanism by which Hyp inhibits cardiac hypertrophy, we examined the ability of Hyp to inhibit fibrosis. Our results showed that interstitial and perivascular fibrosis were dramatically increased in the vehicle-treated hearts subjected to chronic AB, which was limited in Hyp-treated hearts (Fig. 3A-B). Moreover, the mRNA expression levels of fibrotic markers (eg, collagen I, collagen III, and connective tissue growth factor) also demonstrated a blunted fibrotic response in Hyp-treated mice, compared with 
vehicle-treated mice (Fig. 3C). To examine the molecular mechanisms underlying the role of Hyp in collagen synthesis, we assessed the effect of Hyp on Smad cascade activation. The increased levels of transforming growth factor (TGF)- $\beta 1$, Smad2, and Smad3 phosphorylation were attenuated in Hyp-treated mice after AB surgery (Fig. 3D-E). These results indicated that treatment with Hyp could alleviate the fibrotic response induced by chronic pressure overload.

Hyp inhibits inflammatory responses following chronic pressure overload

Inflammation plays an important role in the pathology of cardiovascular diseases [14, 15]. As demonstrated by immunehisto-chemical staining, the number of inflammatory cells (leukocytes and macrophages) infiltrating into the myocardium of Hyp-treated mice

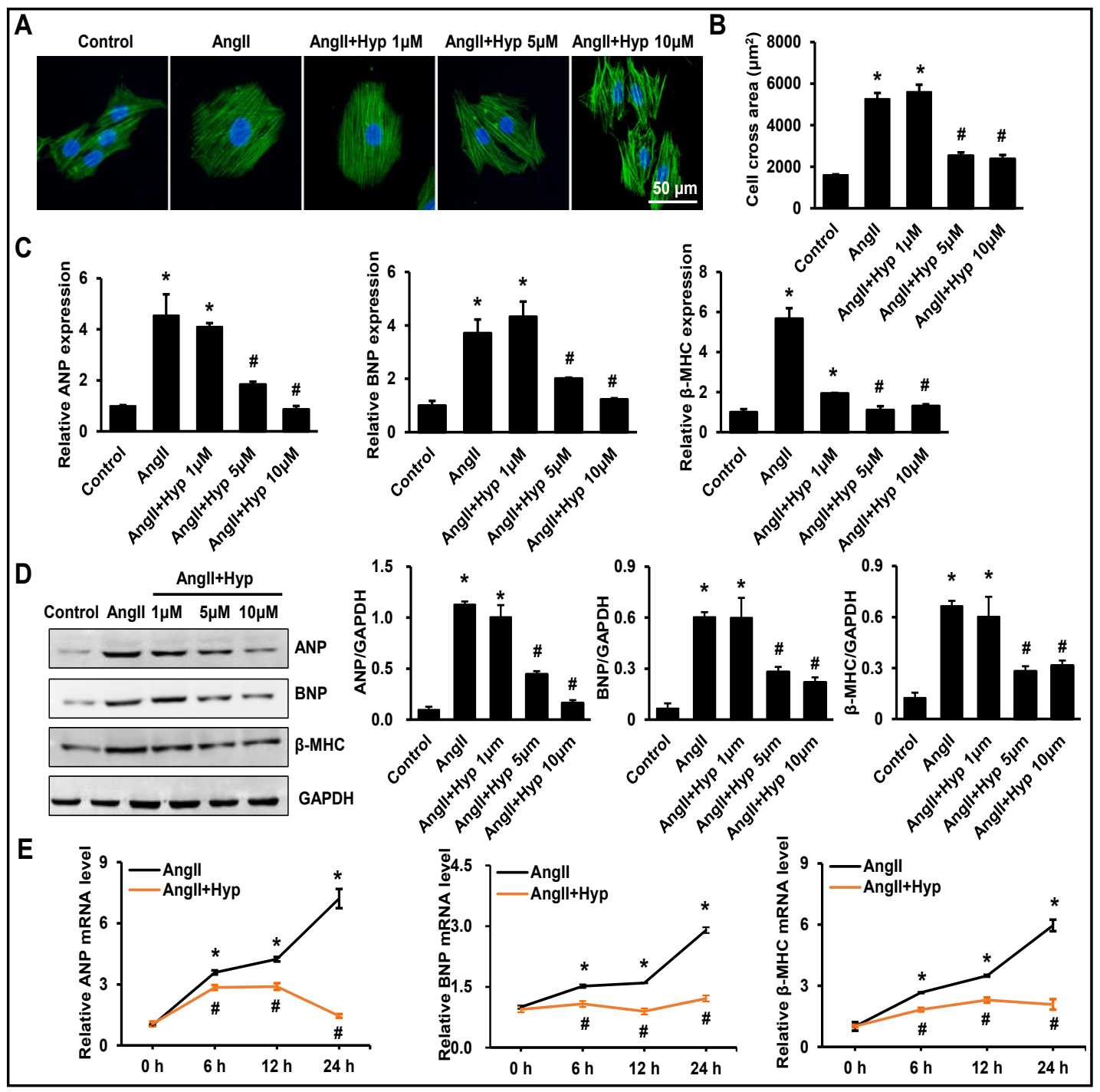

Fig. 1. Hyp suppresses Ang II-induced cardiomyocyte hypertrophy. (A) Representative images of cardiomyocytes treated with $1 \mu \mathrm{M}$ Ang II in the presence of 1, 5, or $10 \mu \mathrm{M}$ Hyp for $24 \mathrm{~h}$. Cardiomyocytes were identified by rhodamine-phalloidin staining (green), and nuclei were stained with DAPI (blue). (B) Quantification of cell surface changes. (C) Real-time PCR analysis of ANP, BNP, and $\beta$-MHC mRNA expression levels in each group $(n=6)$. (D) Western blots of ANP, BNP, and $\beta$-MHC from indicated groups $(n=6)$. (E) Cardiomyocytes were stimulated with Ang II $(1 \mu \mathrm{M})$ and treated with Hyp $(10 \mu \mathrm{M})$ for 0, 6, 12, and $24 \mathrm{~h}$. mRNA levels of ANP, BNP, and $\beta$-MHC in cardiomyocytes in the indicated groups $(n=6) .{ }^{*} \mathrm{P}<0.05$ vs control group; \#P<0.05 vs Ang II-treated cells. 
was significantly decreased after $A B$, compared with vehicle-treated mice (Fig. 4A-C). Moreover, our results showed that, compared with vehicle-treated mice, the mRNA levels of inflammatory factors, including interleukin (IL)-1 $\beta$, IL-6, tumor necrosis factor- $\alpha$ (TNF- $\alpha$ ), and monocyte chemoattractant protein-1 (MCP-1) were decreased in Hyp-treated mice after AB (Fig. 4D). Decreased microvascular density was previously shown to be involved in hypertrophic responses. In the present study, we found that Hyp treatment increased microvascular density in hypertrophic hearts as assessed by CD31 staining (Fig. 4E). These results demonstrate that Hyp inhibits inflammation in response to chronic pressure overload.

\section{Hyp inhibits oxidative stress in vitro and in vivo}

Previous studies have found that Hyp plays an essential role in regulating oxidative stress $[16,17]$. Therefore, we next explored the effect of Hyp on cellular ROS generation. Hyp pretreatment inhibited Ang II-induced ROS generation as assessed by DCFH-DA assay using an enzyme-linked immunosorbent assay reader and light microscopy (Fig. 5A-B). Hyp

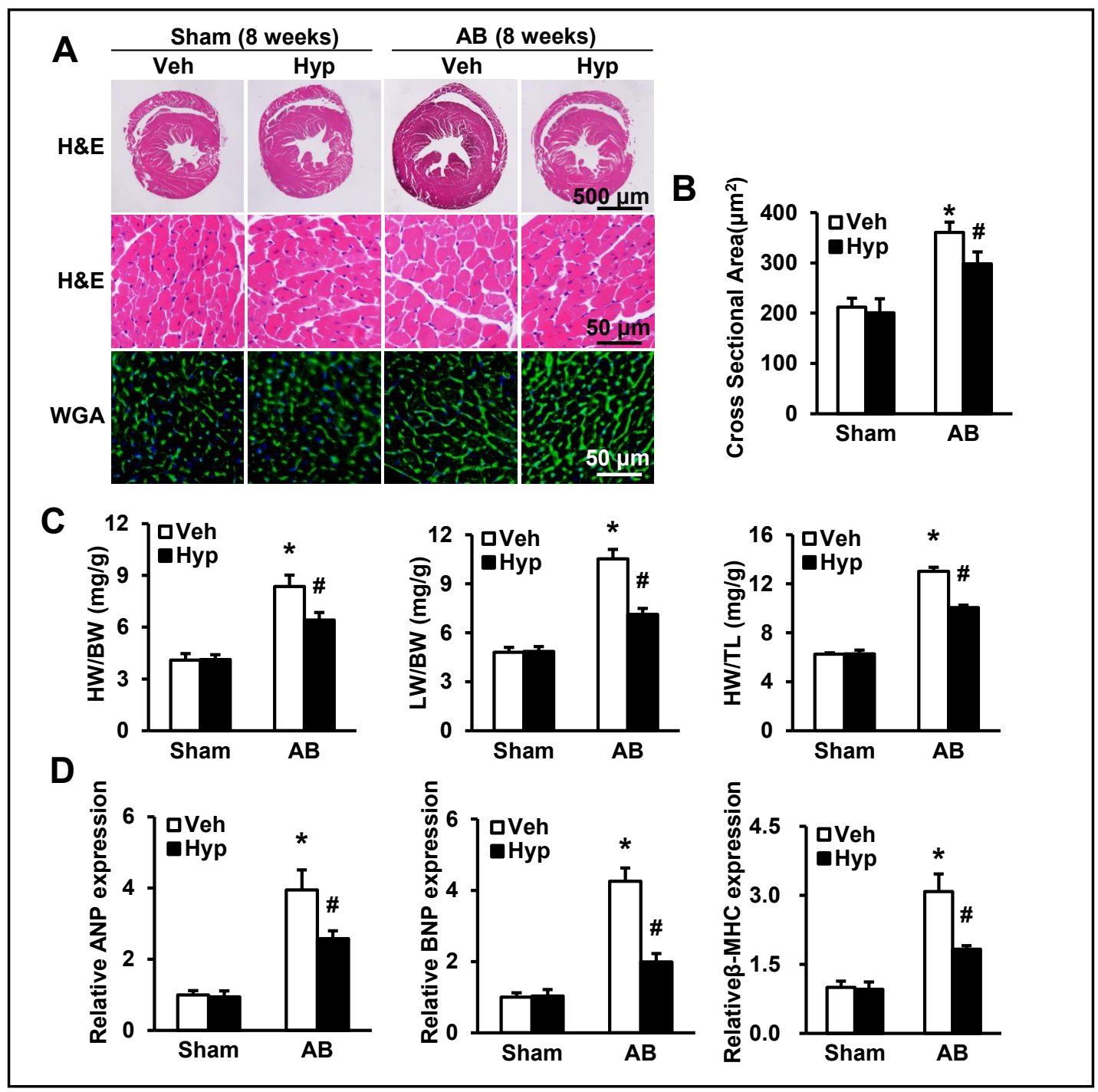

Fig. 2. Hyp reduces cardiac hypertrophy after chronic pressure overload in mice. (A) Histological analyses of HE and WGA staining in all groups at 8 weeks after AB or sham surgery $(n=5-6)$. (B) Cardiomyocyte cross-sectional area ( $n=100+$ cells). (C) Ratios of HW/BW, LW/BW, and HW/TL in the indicated groups (n = 11-14). (D) Real-time PCR analyses of hypertrophic markers (ANP, BNP, $\beta$-MHC) induced by AB surgery in the indicated groups $(\mathrm{n}=6)$. ${ }^{*} \mathrm{P}<0.05$ vs Veh-Sham; $\# \mathrm{P}<0.05$ vs Veh-AB. 
Table 3. Parameters in in the indicated groups. BW, body weight; HW, heart weight; LW, lung weight; TL, tibia length; HR, heart rate; LVEDD, left ventricular end-diastolic diameter; LVESD, left ventricular end-systolic diameter; FS, fractional shortening; LVESP=Left ventricular End-systolic Pressure. LVEF=Left ventricular ejection fraction. ${ }^{*} \mathrm{P}<0.05$ vs Veh-Sham; ${ }^{~} \mathrm{P}<0.05$ vs Veh-AB

\begin{tabular}{lcccc}
\hline Parameter & Veh-Sham mice $(\mathrm{n}=11)$ & Hyp-Sham mice $(\mathrm{n}=12)$ & Veh-AB mice $(\mathrm{n}=11)$ & Hyp-AB mice $(\mathrm{n}=10)$ \\
\hline BW (g) & $27.53 \pm 0.38$ & $27.59 \pm 0.61$ & $28.49 \pm 0.44$ & $28.65 \pm 0.25$ \\
HW/BW(mg/g) & $4.09 \pm 0.08$ & $4.13 \pm 0.09$ & $8.35 \pm 0.16^{*}$ & $6.42 \pm 0.13^{\#}$ \\
LW/BW(mg/mg) & $4.81 \pm 0.10$ & $4.85 \pm 0.11$ & $10.53 \pm 0.58^{*}$ & $7.12 \pm 0.16^{\#}$ \\
HW/TL(mg/mm) & $6.26 \pm 0.11$ & $6.27 \pm 0.13$ & $13.02 \pm 0.33^{*}$ & $10.07 \pm 0.20^{\#}$ \\
HR (beats/min) & $544 \pm 13$ & $513 \pm 21$ & $509 \pm 18$ & $532 \pm 22$ \\
LVEDD(mm) & $3.68 \pm 0.05$ & $3.72 \pm 0.06$ & $5.03 \pm 0.19^{*}$ & $4.42 \pm 0.17^{\#}$ \\
LVESD(mm) & $2.11 \pm 0.06$ & $2.23 \pm 0.04$ & $3.79 \pm 0.08^{*}$ & $3.09 \pm 0.11^{\#}$ \\
FS (\%) & $42.1 \pm 0.74$ & $41.2 \pm 0.29$ & $27.8 \pm 0.86^{*}$ & $30.6 \pm 0.94^{\#}$ \\
LVESP (mmHg) & $121.3 \pm 4.68$ & $112.6 \pm 4.98$ & $159.6 \pm 7.41^{*}$ & $148.4 \pm 5.13^{*}$ \\
LVEF (\%) & $54.9 . \pm 3.2$ & $52.8 \pm 4.3$ & $30.5 \pm 3.8^{*}$ & $4796.5 \pm 612.1^{*}$ \\
dp/dt max (mmHg/sec) & $9883.2 \pm 413.7$ & $10231.8 \pm 512.3$ & $8735.4 \pm 478.4^{\#}$ \\
dp/dt min (mmHg/sec) & $-8925.6 \pm 431.2$ & $-8846.4 \pm 389.0$ & $-5063.6 \pm 462.1^{*}$ & $-7902.3 \pm 369.3^{\#}$ \\
\hline
\end{tabular}

Fig. 3. Нyp a t te nu a te s cardiac fibrosis induced by p re s s u re overload in mice. (A) PSR staining of histological sections of the LV in the i $\mathrm{n} \mathrm{di} \mathrm{c} \mathrm{a} \mathrm{te} \mathrm{d}$ groups 4 weeks post-AB surgery (n = 6). (B) Fibrotic areas were quantified using an imagea $\mathrm{n}$ a $\mathrm{l}$ y z i $\mathrm{n}$ g system $(\mathrm{n}=33-$ 36 fields). (C) Real-time PCR analyses of the fibrotic markers (collagen I, collagen III, and connective tissue growth factor) in the

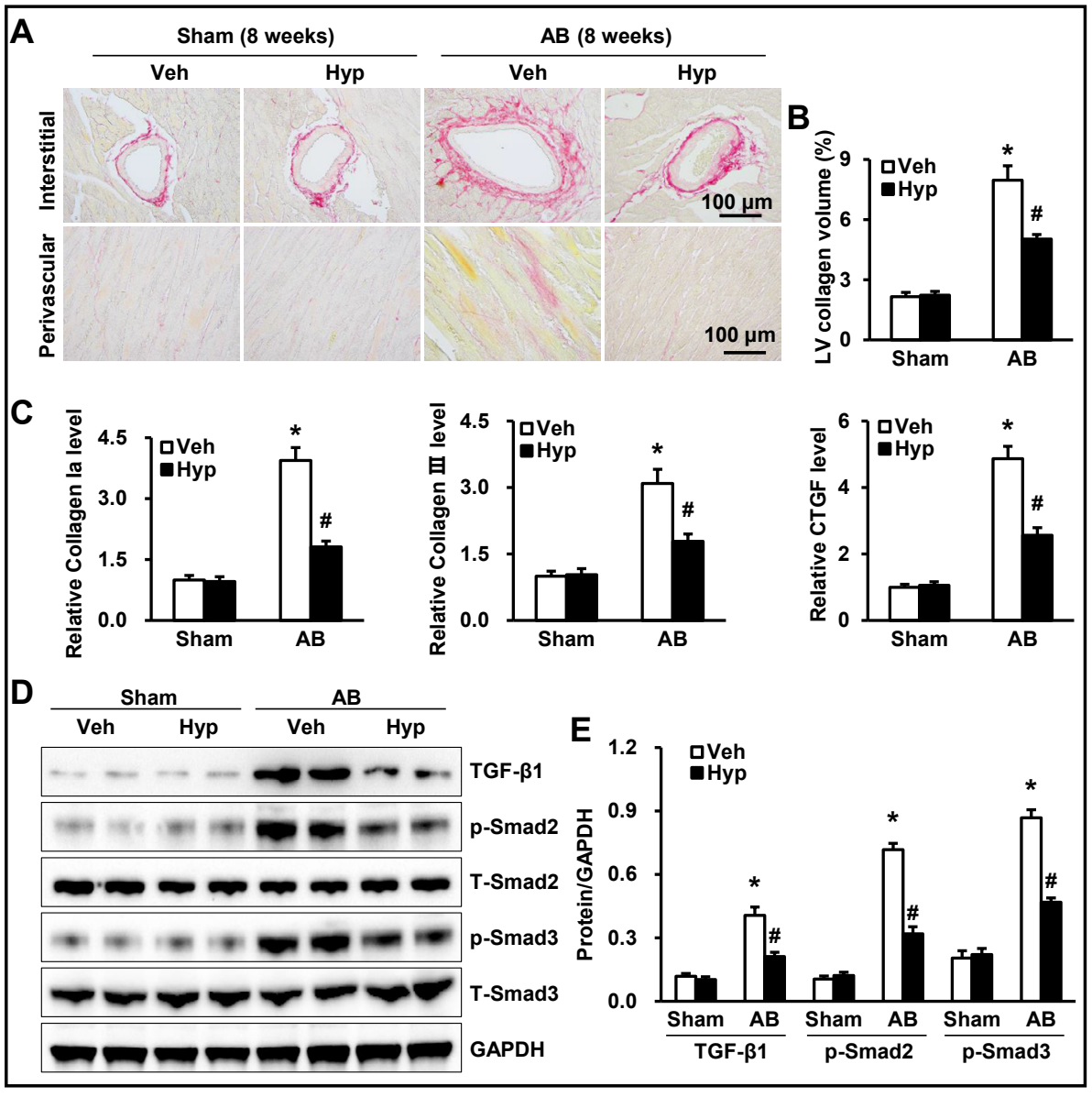
i n d i c a t e d groups $(n=6)$. (D) Western blots of TGF- $\beta 1$, phosphorylated (p)-Smad2, p-Smad3, total (T)-Smad2, and $\mathrm{T}$-Smad3 from the indicated groups $(\mathrm{n}=6)$. (E) Quantitative western blotting analysis. ${ }^{*} \mathrm{P}<0.05$ vs Veh-Sham; $\# \mathrm{P}<0.05$ vs Veh-AB. 


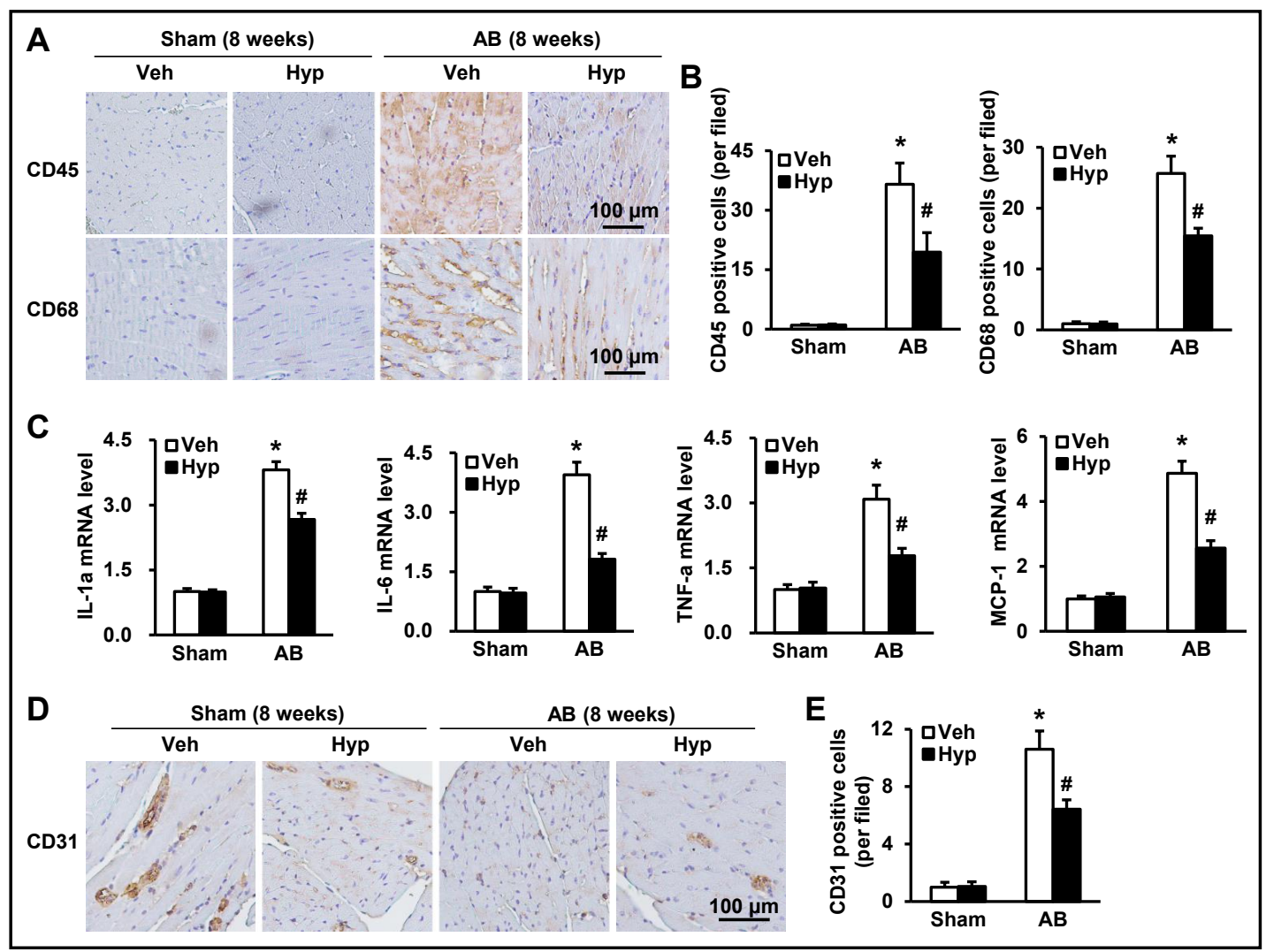

Fig. 4. Hyp inhibits inflammatory responses following chronic pressure overload. (A) Immunohistochemical staining of CD45 and CD68 in mouse hearts in the indicated groups (n = 6). (B) Quantification of CD45and CD68-positive cells in mouse hearts in the indicated groups $(n=10+$ fields). C: Quantification of IL1a, IL-6, TNF- $\alpha$, and MCP-1 mRNA levels by real-time PCR ( $n=6)$. (D) Detection of microvessel density by immunohistochemical staining of CD31 in the indicated mice 8 weeks post-AB surgery $(n=6)$. (E) Quantification of CD31-positive cells in mouse hearts in the indicated groups ( $\mathrm{n}=10+$ fields). ${ }^{*} \mathrm{P}<0.05$ vs Veh-Sham; \#P<0.05 vs Veh-AB.

pretreatment also increased the mRNA levels of superoxide dismutase (SOD) and glutathione peroxidase (Gpx) and decreased the mRNA levels of nicotinamide adenine dinucleotide phosphate-oxidase (NADPH) P67 phox in cardiomyocytes (Fig. 5C). We also observed increased activity of Gpx and SOD in Hyp-treated mouse hearts (Fig. 5D-E). Consistently, decreased levels of the lipid peroxidation product 4-hydroxynonenal were observed in Hyptreated mice compared with vehicle-treated animals (Fig. 5F). Hyp treatment increased the protein levels of SOD and Gpx and decreased the protein levels of P67 phox in mouse hearts (Fig. 5G-H). Altogether, the above results suggested that Hyp pretreatment could inhibit oxidative stress both in vitro and in vivo.

\section{Hyp inhibits the AKT signaling pathway in response to hypertrophic stimuli}

The above results suggested that Hyp protects against pressure overload-induced cardiac remodeling. However, the molecular mechanism by which Hyp regulates the hypertrophic response remains unknown. Given that the AKT signaling pathway has been demonstrated to play an important part in the development of cardiac hypertrophy, we first examined whether Hyp affected AB-induced activation of the AKT signaling pathway. We exposed NRCMs to $1 \mu \mathrm{M}$ Ang II for $48 \mathrm{~h}$ with or without pretreatment with $10 \mu \mathrm{M}$ Hyp. Of interest, we observed that Ang II induced significant activation of the AKT pathway. However, Hyp pretreatment markedly suppressed the activation of AKT, GSK3 $\beta$, mTOR, and eIF4e (Fig. $6 \mathrm{~A}-\mathrm{B})$. In line with the in vitro findings, $\mathrm{AB}$ induced a significant increase in phosphorylated 
levels of AKT, GSK3 $\beta$, mTOR, and eIF4e. Nevertheless, activation of AKT, GSK3 $\beta$, mTOR, and eIF4e was blocked in Hyp-treated mouse hearts (Fig. 6C-D). Taken together, these results demonstrated that Hyp may suppress cardiac hypertrophy through inhibition of AKT signaling in vitro and in vivo.

Protective effect of Hyp against cardiac hypertrophy was largely dependent on regulation of the AKT signaling pathway

In order to confirm that Hyp inhibited cardiomyoctye hypertrophy via inhibition of the AKT signaling pathway, we performed additional in vitro experiments. NRCMs were treated with MK-2206, a novel orally active allosteric AKT inhibitor [18], for $1 \mathrm{~h}$ and then with Ang II for $48 \mathrm{~h}$ after treatment with Hyp for $24 \mathrm{~h}$. As expected, MK-2206 significantly attenuated Ang II-induced cell enlargement and the expression levels of hypertrophic biomarkers. However,

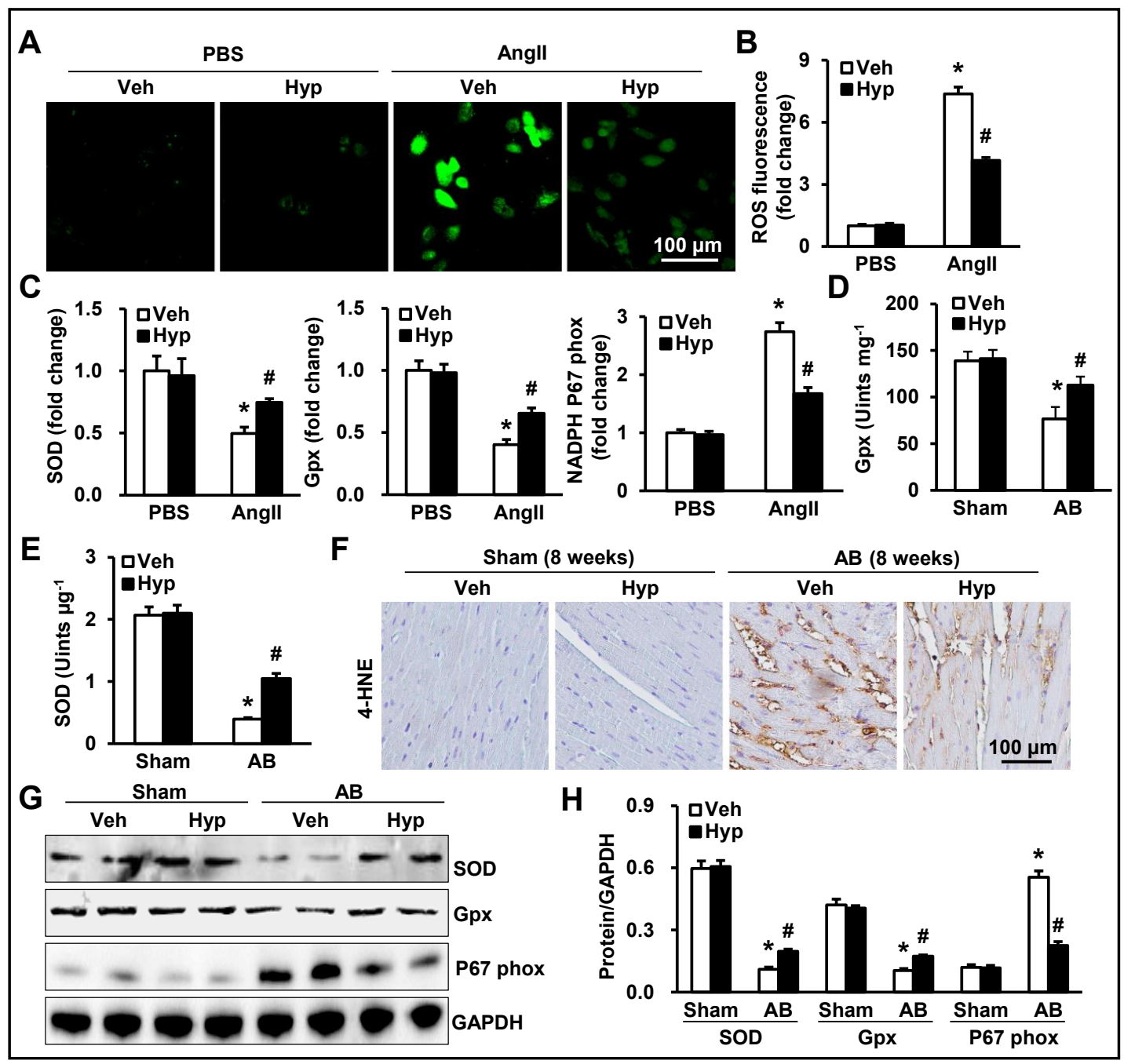

Fig. 5. Hyp inhibits oxidative stress in hypertrophic hearts and cardiomyocytes. (A) ROS are detected by DCFH-DA with light microscopy $(n=6)$. (B) ROS are detected by an enzyme-linked immunosorbent assay (ELISA) reader $(n=6)$. (C) Real-time PCR analyses of oxidative markers (SOD, Gpx, NADPH p67 phox; $n$ =6). (D) Gpx activity in the indicated groups $(n=6)$. (E) SOD activity in the indicated groups $(n=6)$. $(F)$ Immunohistochemical staining of 4-hydroxynonenal (4-HNE) in the indicated groups 4 weeks post- $\mathrm{AB}$ surgery $(n=6)$. (G) Western blots of SOD, Gpx, and NADPH p67 phox from the indicated groups $(n=6)$. $(H)$ Quantitative western blotting analysis. ${ }^{*} \mathrm{P}<0.05$ vs Veh-Sham; \# $\mathrm{P}<0.05$ vs Veh-AB. 


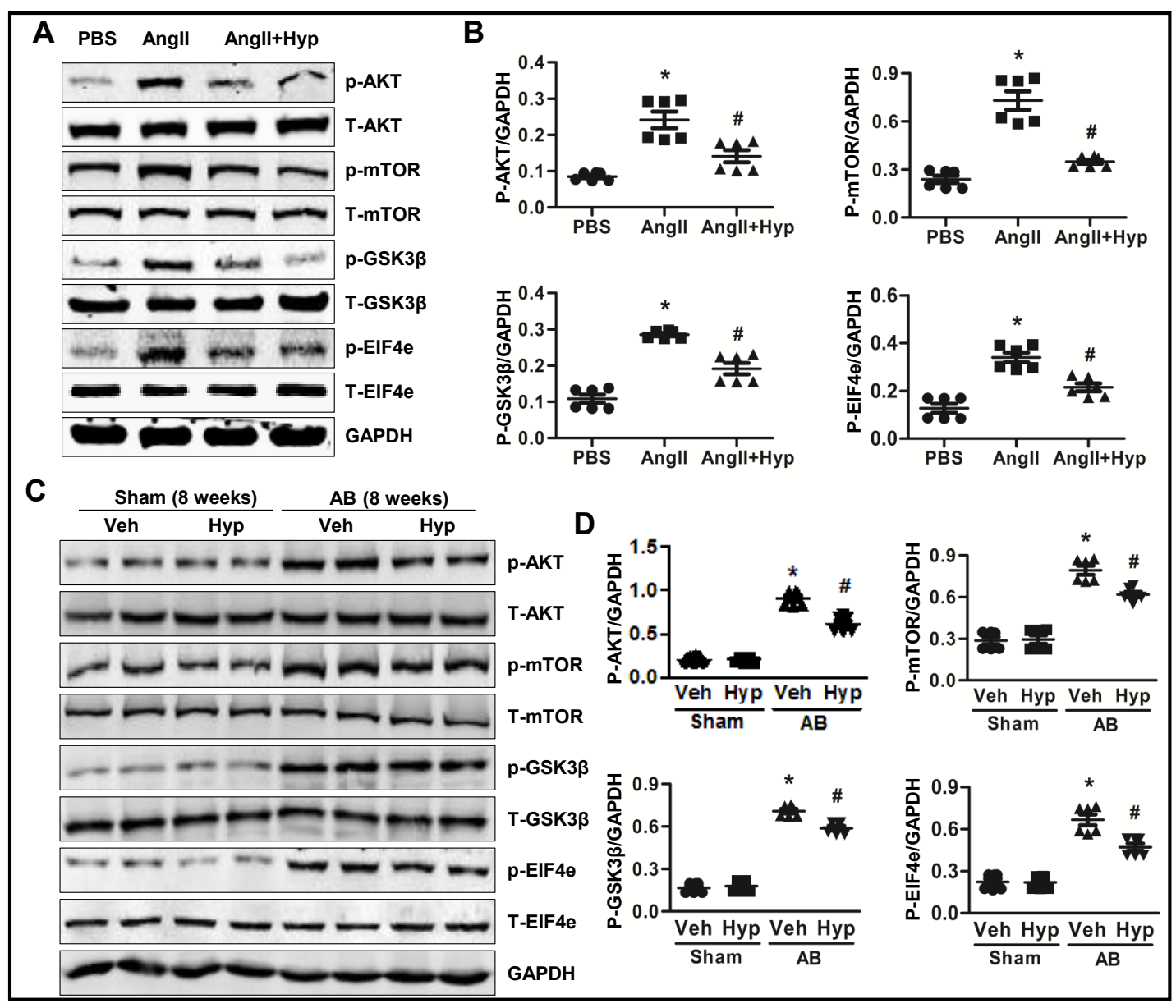

Fig. 6. Hyp blocks AKT signaling in vivo and in vitro. (A) Representative blots of phosphorylated (p) and total (T) AKT, mTOR, GSK3 $\beta$, and eIF-4E in the cardiomyocytes in the indicated groups $(n=6)$. (B) Comparison of expression among the indicated groups. ${ }^{*} \mathrm{P}<0.05$ vs $\mathrm{PBS}$ group. $\# \mathrm{P}<0.05$ vs Ang II group. (C) Representative blots of phosphorylated and total AKT, mTOR, GSK3 $\beta$, and eIF-4E in the heart tissues of mice in the indicated groups $(n=6)$. (D) Comparison of expression among the indicated groups. ${ }^{*} \mathrm{P}<0.05$ vs Veh-Sham; $\# \mathrm{P}<0.05$ vs Veh-AB.

Hyp did not affect the decreased hypertrophic response in MK-2206-treated cells (Fig. $7 \mathrm{~A}-\mathrm{C}$ ). Moreover, we found that MK-2206 significantly inhibited Ang II-induced oxidative stress, whereas Hyp did not affect the decreased oxidative stress in MK-2206-treated cells (Fig. 7D-F). Collectively, these findings confirm the protective effect of Hyp against cardiac hypertrophy through blockade of activation of the AKT signaling pathway.

\section{Discussion}

Although hypertrophy is initially a compensatory mechanism, sustained cardiac hypertrophy ultimately leads to decompensated heart failure [3]. Much research has been conducted to investigate the progression of cardiac hypertrophy to heart failure, but the mechanism by which this process is suppressed remains unclear. Therefore, it is crucial to clarify the molecular mechanism underlying cardiac hypertrophy and the function of antihypertrophic targets. In recent decades, various signaling pathways that mediate the process of hypertrophic development have been identified, such as MAPKs, calcineurin/NFAT, and PI3K/AKT pathways. Blocking these signaling pathways effectively may provide a promising method for inhibiting cardiac hypertrophy and heart failure. The present challenge is to 


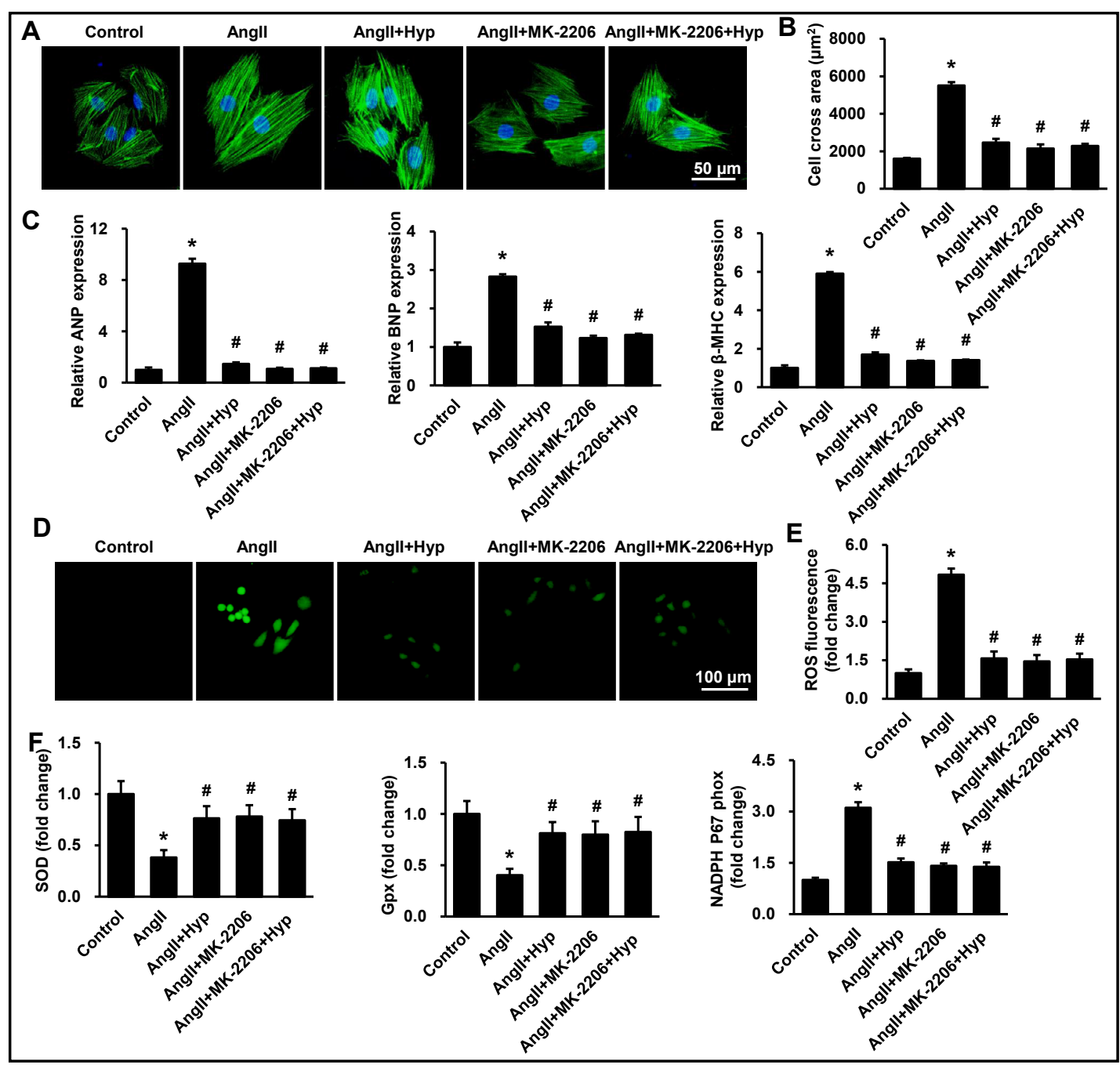

Fig. 7. Hyp-mediated cardiac hypertrophy is largely dependent on regulation of the AKT signaling pathway. (A) Detection of cell surface area by immunofluorescence staining of $\alpha$-actinin in the indicated groups ( $\mathrm{n}=$ 6). Cardiomyocytes were identified by $\alpha$-actinin staining (green), and nuclei were stained with DAPI (blue). (B) Quantitative results ( $\mathrm{n}=50+$ cells per group). (C) Real-time PCR analyses of hypertrophic markers in the indicated groups $(n=6)$. (D) ROS detected by DCFH-DA with light microscopy in the indicated groups $(n=6)$. (E) ROS detected by an ELISA reader in the indicated groups $(n=6)$. (F) Real-time PCR analyses of oxidative markers in the indicated groups $(n=6)$. ${ }^{*} \mathrm{P}<0.05$ vs control group; $\# \mathrm{P}<0.05$ vs Ang II-treated group.

identify pharmacological agents that selectively modulate specific signaling pathways and thereby prevent pathological cardiac hypertrophy. To date, no effective drugs have been found to treat cardiac hypertrophy-related molecular changes. In this study, our in vitro study revealed that Hyp could prevent Ang II-induced cardiomyocyte hypertrophy. Moreover, by using a mechanical overload induced cardiac remodeling model, our data showed that Hyp can inhibit cardiac hypertrophy, fibrosis, inflammation, and oxidative stress in response to stress in vivo. In addition, we demonstrated that Hyp ameliorated cardiac hypertrophy partially by modulating the AKT signaling pathway. To our knowledge, our study is the first to demonstrate that Hyp can alleviate adverse cardiac remodeling and regulate hypertrophic signaling due to chronic pressure overload. 
Studies have explored the anti-viral, anti-inflammatory, anti-oxidant, and anti-cancer activities of Hyp $[19,20]$. In addition, Hyp was reported to exert beneficial cardiovascular effects, such as anti-ischemic [21] and anti-depressant [22] activities, and cytoprotective properties against oxidative stress [23]. It was previously reported that Hyp significantly improved LV end-diastolic pressure and LV developed pressure induced by ischemia/ reperfusion injury via activation of Nrf2 signaling [9]. In addition, Li et al. demonstrated that Hyp could induce apoptosis and inhibit growth via the NF-kB signaling pathway both in vitro and in vivo [10]. However, the potential role of Hyp and its mechanism of action in cardiac hypertrophy remain unknown. Here, we revealed that Hyp is an anti-hypertrophic factor that attenuates cardiac hypertrophy by blocking activation of the AKT signaling pathway.

Cardiac fibrosis is a major feature of hypertrophic cardiomyopathy and contributes to ventricular dysfunction and life-threatening arrhythmia [13, 24]. Our in vivo study showed that Hyp treatment reduced the pressure overload-induced fibrotic response. We examined the role of TGF- $\beta /$ Smad signaling in the progression of fibrosis. We found that expression levels of TGF- $\beta 1, p$-Smad2, and p-Smad3 induced by pressure overload were attenuated in Hyp-treated mice, which is consistent with previous findings [25]. Our data showed that Hyp reduced TGF- $\beta /$ Smad signaling in hypertrophied hearts and inhibited collagen synthesis.

Mounting evidence has strongly suggested that inflammation plays a critical role in the development of cardiac hypertrophy and heart failure $[14,15]$. In this study, we discovered that Hyp treatment was able to repress inflammatory cell infiltration into the myocardium of $\mathrm{AB}$ mice. Moreover, levels of inflammatory cytokines, such as IL-1a, IL-6, TNF- $\alpha$, and MCP-1, which promote progression of cardiac hypertrophy and heart failure, increased in the hypertrophic hearts [26] but were normalized by Hyp treatment. We speculate that the protective effects of Hyp on cardiac dysfunction after $A B$ surgery may be partially associated with the suppression of cardiac inflammation.

Evidences suggest that oxidative stress is a crucial factor in the development and progression of cardiac hypertrophy, as it is involved in various molecular mechanisms that contribute to cellular dysfunction, protein and lipid peroxidation, and DNA damage and can lead to irreversible cell damage and death $[27,28]$. In parallel, oxidative stress has a role in the regulation of cell signaling in cardiomyocytes under afterload stress conditions, favoring maladaptive cardiac remodeling $[29,30]$. During our investigations into the mechanism responsible for Hyp-mediated protection against pathological cardiac remodeling, we demonstrated a dramatic suppression of oxidative stress by Hyp following hypertrophic stress.

The role of the AKT signaling pathway in cardiac hypertrophy has been well established [31]. Targeted overexpression of constitutively active AKT in the heart increased organ size, while expression of a dominant-negative mutant resulted in the opposite outcome [32]. The hypertrophic response following AKT activation was apparently associated with the AKT downstream targets GSK3 $\beta$ and mTOR [33]. Increasing evidence suggests that GSK3 $\beta$ functions as a negative regulator of cardiac hypertrophy that blocks cardiomyocyte hypertrophy in response to endothelin 1, Ang II, phenylephrine, or isoproterenol [34]. AKT signaling pathway target mTOR appears critical for cardiac hypertrophy during chronic pressure overload or neurohumoral factors [33]. Activation of mTOR and its downstream target eIF4e mediates cardiomyocyte protein synthesis, which is associated with cardiac angiogenesis, fibrosis, and hypertrophy [35]. An important finding of the present study is that the increases in AKT, GSK3 $\beta$, mTOR, and eIF4e phosphorylation levels in response to hypertrophic stress were largely blocked by Hyp. Our additional in vivo experiments confirmed that Hyp attenuates cardiac hypertrophy by blocking activation of the AKT signaling pathway. Therefore, Hyp could attenuate cardiac hypertrophy in response to hypertrophic stress via inhibition of AKT signaling.

\section{Conclusion}

In this study, Hyp was administrated 1 week after AB surgery, which suggests that Hyp could be a potential novel treatment for established cardiac remodeling. Yet, in vitro, Hyp was administered $24 \mathrm{~h}$ before Ang II stimulation, which implies that Hyp may be a potential new strategy to prevent cardiac remodeling before it is established. In summary, the present findings provide the first evidence that Hyp protects against cardiac hypertrophy in response 


\section{Cellular Physiology Cell Physiol Biochem 2018;51:827-841

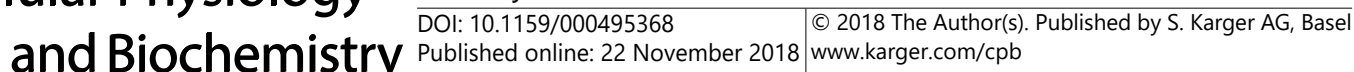

Wang et al.: Hyperoside Modulates Cardiac Hypertrophy

to hypertrophic stress. Our results demonstrate for the first time that Hyp attenuates cardiac hypertrophy via inhibition of the AKT signaling pathway. Therefore, Hyp may offer a potentially effective option for prevention and treatment of cardiac remodeling induced by chronic pressure overload. However, future studies and clinical trials are needed to confirm the potential clinical importance of Hyp.

\section{Acknowledgements}

This study was supported by the National Natural Science Foundation of China (Grant Nos. 81400323, 81600191, and 81600189), the Medical Science and Technology Research Project of Henan Province (Grant No. 201702063), the Scientific and Technological Project of Henan Province (Grant No. 172102310531), and the Key Scientific Research Project of Henan Province College (Grant No. 15A320029).

\section{Disclosure Statement}

The authors declare that there are no conflicts of interest regarding the publication of this paper.

\section{References}

1 Li Q Xie J, Wang B, Li R, Bai J, Ding L, Gu R, Wang L, Xu B: Overexpression of microRNA-99a attenuates cardiac hypertrophy. PLoS One 2016;11:e0148480.

$>2$ Wu QQ, Xiao Y, Yuan Y, Ma ZG, Liao HH, Liu C, Zhu JX, Yang Z, Deng W, Tang QZ: Mechanisms contributing to cardiac remodelling. Clin Sci (Lond) 2017;131:2319-2345.

3 Frey N, Katus HA, Olson EN, Hill JA: Hypertrophy of the heart: a new therapeutic target? Circulation 2004;109:1580-1589.

-4 Heineke J, Molkentin JD: Regulation of cardiac hypertrophy by intracellular signalling pathways. Nat Rev Mol Cell Biol 2006;7:589-600.

$>5$ Kim SJ, Um JY, Lee JY.: Anti-inflammatory activity of hyperoside through the suppression of nuclear factor$\kappa B$ activation in mouse peritoneal macrophages. Am J Chin Med 2011;39:171-181.

-6 Li W, Liu M, Xu YF, Feng Y, Che JP, Wang GC, Zheng JH.: Combination of quercetin and hyperoside has anticancer effects on renal cancer cells through inhibition of oncogenic microRNA-27a. Oncol Rep 2014;31:117-124.

7 Zou L, Chen S, Li L, Wu T: The protective effect of hyperoside on carbon tetrachloride-induced chronic liver fibrosis in mice via upregulation of Nrf2. Exp Toxicol Pathol 2017;69:451-460.

8 Xiao R, Xiang AL, Pang HB, Liu KQ: Hyperoside protects againsthypoxia/reoxygenation induced injury in cardiomyocytes by suppressing the Bnip3 expression. Gene 2017;629:86-91.

-9 Hou JY, Liu Y, Liu L, Li XM: Protective effect of hyperoside on cardiac ischemia reperfusion injury through inhibition of ER stress and activation of Nrf2 signaling. Asian Pac J Trop Med 2016;9:76-80.

10 Li Y, Wang Y, Li L, Kong R, Pan S, Ji L, Liu H, Chen H, Sun B: Hyperoside induces apoptosis and inhibits growth in pancreatic cancer via Bcl-2 family and NF-kappaB signaling pathway both in vitro and in vivo. Tumour Biol 2016;37:7345-7355.

11 Wu QQ, Xu M, Yuan Y, Li FF, Yang Z, Liu Y, Zhou MQ, Bian ZY, Deng W, Gao L, Li H, Tang QZ: Cathepsin B deficiency attenuates cardiac remodeling in response to pressure overload via TNF-alpha/ASK1/JNK pathway. Am J Physiol Heart Circ Physiol 2015;308:H1143-1154.

12 Gao L, Yao R, Liu Y, Wang Z, Huang Z, Du B, Zhang D, Wu L, Xiao L, Zhang Y: Isorhamnetin protects against cardiac hypertrophy through blocking PI3K-AKT pathway. Mol Cell Biochem 2017;429:167-177.

13 Liu Y, Gao L, Guo S, Liu Y, Zhao X, Li R, Yan X, Li Y, Wang S, Niu X, Yao L, Zhang Y, Li L, Yang H: Kaempferol Alleviates Angiotensin II-Induced Cardiac Dysfunction and Interstitial Fibrosis in Mice. Cell Physiol Biochem 2017;43:2253-2263.

14 Bian Z, Cong J, Shen DF, Chen L, Yan L, Tang Q, Li H.: Cellular repressor of E1A-stimulated genes attenuates cardiac hypertrophy and fibrosis. J Cell Mol Med 2009;13:1302-1313. 


\section{Cellular Physiology Cell Physiol Biochem 2018;51:827-841 and Biochemistry \begin{tabular}{l|l} 
DOI: 10.1159/000495368 2018 The Author(s). Published by S. Karger AG, Basel \\
Published
\end{tabular}

Wang et al.: Hyperoside Modulates Cardiac Hypertrophy

15 Qi HP, Wang Y, Zhang QH, Guo J, Li L, Cao YG, Li SZ, Li XL, Shi MM, Xu W, Li BY, Sun HL: Activation of peroxisome proliferator-activated receptor $\gamma$ (PPAR $\gamma$ ) through NF- $\kappa$ B/Brg1 and TGF- $\beta 1$ pathways attenuates cardiac remodeling in pressure-overloaded rat hearts. Cell Physiol Biochem 2015;35:899-912.

16 An X, Zhang L, Yuan Y, Wang B, Yao Q, Li L, Zhang J, He M, Zhang J: Hyperoside pre-treatment prevents glomerular basement membrane damage in diabetic nephropathy by inhibiting podocyte heparanase expression. Sci Rep 2017; 7:6413.

-17 Park JY, Han X, Piao MJ, Oh MC, Fernando PM, Kang KA, Ryu YS, Jung U, Kim IG, Hyun JW: Hyperoside Induces Endogenous Antioxidant System to Alleviate Oxidative Stress. J Cancer Prev 2016;21:41-47.

18 Lindsley CW, Barnett SF, Layton ME, Bilodeau MT: The PI3K/Akt pathway: recent progress in the development of ATP-competitive and allosteric Akt kinase inhibitors. Curr Cancer Drug Targets 2008;8:718.

19 Middleton E, Jr., Kandaswami C, Theoharides TC: The effects of plant flavonoids on mammalian cells: implications for inflammation, heart disease, and cancer. Pharmacol Rev 2000;52:673-751.

20 Havsteen BH: The biochemistry and medical significance of the flavonoids. Pharmacol Ther 2002;96:67202.

21 Bernatoniene J, Trumbeckaite S, Majiene D, Baniene R, Baliutyte G, Savickas A, Toleikis A: The effect of crataegus fruit extract and some of its flavonoids on mitochondrial oxidative phosphorylation in the heart. Phytother Res 2009;23:1701-1707.

22 Schettler V, Methe H, Staschinsky D, Schuff-Werner P, Muller GA, Wieland E: Review: the oxidant/ antioxidant balance during regular low density lipoprotein apheresis. Ther Apher 1999;3:219-226.

-23 Piao MJ, Kang KA, Zhang R, Ko DO, Wang ZH, You HJ, Kim HS, Kim JS, Kang SS, Hyun JW: Hyperoside prevents oxidative damage induced by hydrogen peroxide in lung fibroblast cells via an antioxidant effect. Biochim Biophys Acta 2008;1780:1448-1457.

-24 Gao L, Huang K, Jiang DS, Liu X, Huang D, Li H, Zhang XD, Huang K: Novel role for caspase-activated DNase in the regulation of pathological cardiac hypertrophy. Hypertension 2015;65:871-881.

25 Zhang N, Ying MD, Wu YP, Zhou ZH, Ye ZM, Li H, Lin DS: Hyperoside, a flavonoid compound, inhibits proliferation and stimulates osteogenic differentiation of human osteosarcoma cells. PLoS One 2014;9:e98973.

-26 Wu QQ, Yuan Y, Jiang XH, Xiao Y, Yang Z, Ma ZG, Liao HH, Liu Y, Chang W, Bian ZY, Tang QZ: OX40 regulates pressure overload-induced cardiac hypertrophy and remodelling via CD4+ T-cells. Clin Sci (Lond) 2016;130:2061-2071.

27 Seddon M, Looi YH, Shah AM: Oxidative stress and redox signalling in cardiac hypertrophy and heart failure. Heart 2007;93:903-907.

-28 Drozdz D, Kwinta P, Sztefko K, Kordon Z, Drozdz T, Latka M, Miklaszewska M, Zachwieja K, Rudzinski APietrzyk JA: Oxidative Stress Biomarkers and Left Ventricular Hypertrophy in Children with Chronic Kidney Disease. Oxid Med Cell Longev 2016;2016:7520231.

29 Ohta Y, Kinugawa S, Matsushima S, Ono T, Sobirin MA, Inoue N, Yokota T, Hirabayashi K, Tsutsui H: Oxidative stress impairs insulin signal in skeletal muscle and causes insulin resistance in postinfarct heart failure. Am J Physiol Heart Circ Physiol 2011;300:H1637-1644.

-30 Giussani DA, Camm EJ, Niu Y, Richter HG, Blanco CE, Gottschalk R, Blake EZ, Horder KA, Thakor AS, Hansell JA, Kane AD, Wooding FB, Cross CMHerrera EA: Developmental programming of cardiovascular dysfunction by prenatal hypoxia and oxidative stress. PLoS One 2012;7:e31017.

-31 Rohini A, Agrawal N, Koyani CNSingh R: Molecular targets and regulators of cardiac hypertrophy. Pharmacol Res 2010;61:269-280.

32 Shioi T, McMullen JR, Kang PM, Douglas PS, Obata T, Franke TF, Cantley LCIzumo S: Akt/protein kinase B promotes organ growth in transgenic mice. Mol Cell Biol 2002;22:2799-2809.

33 Ikeda M, Ide T, Fujino T, Matsuo Y, Arai S, Saku K, Kakino T, Oga Y, Nishizaki A, Sunagawa K: The Akt-mTOR axis is a pivotal regulator of eccentric hypertrophy during volume overload. Sci Rep 2015;5:15881.

-34 Haq S, Choukroun G, Kang ZB, Ranu H, Matsui T, Rosenzweig A, Molkentin JD, Alessandrini A, Woodgett J, Hajjar R, Michael A, Force T: Glycogen synthase kinase-3beta is a negative regulator of cardiomyocyte hypertrophy. J Cell Biol 2000;151:117-130.

-35 Wu QQ, Zong J, Gao L, Dai J, Yang Z, Xu M, Fang Y, Ma ZG, Tang QZ: Sulforaphane protects H9c2 cardiomyocytes from angiotensin II-induced hypertrophy. Herz 2014;39:390-396. 